\title{
Project Sizing and Estimating: A Case Study Using PSU, IFPUG and COSMIC
}

\author{
Luigi Buglione ${ }^{1}$, Juan J. Cuadrado-Gallego ${ }^{2}$, and J. Antonio Gutiérrez de Mesa ${ }^{2}$ \\ ${ }^{1}$ École de Technologie Supérieure (ÉTS) / Engineering.it \\ luigi.buglione@eng. it \\ ${ }^{2}$ Universidad de Alcalá. Edificio Politécnico. Autovía A2, Km. 31, \\ 7. 28805 - Alcalá de Henares, Madrid, Spain \\ $\{j$ jcg, jagutierrez\} @uah.es
}

\begin{abstract}
From the late '70s on, Albrecht's Function Point Analysis provided an insightful way to size a software system moving from the elicitation of Functional User Requirement (FUR), making an evaluation more objective than done before using Lines of Code (LOC). This technique has currently a plenty of variants, some of them become international de jure standards (e.g. COSMIC, NESMA, Mark-II and FISMA) - called FSM (Functional Size Measurement) methods - and they are widely adopted worldwide. A common problem when using a FSM for estimation purposes is that the software size (that is a product measure, referring only to its functional side) is used as the solely independent variable to estimate the overall project effort, that includes the effort of both the functional and non-functional activities within the project's boundary, as currently stressed more and more in the Scope Management field, also in the Software Engineering domain (see NorthernScope and SouthernScope approaches), not knowing neither the approximated distribution between the two parts. This missing information, usually not gathered in projects' repositories, can be one of the reasons leading to a lower capability in estimating project effort.

In 2003, a new technique called PSU (Project Size Unit) come out with the aim to size the 'project' entity from a Project Management viewpoint. It can be used alone or jointly with a FSM unit. In the second case, the joint usage of the two values can improve what a FSM cannot measure and therefore estimate, that is the non-functional side of a software project. This paper presents a case study with 33 projects measured both with IFPUG FPA and COSMIC methods as well as with PSU, showing the obtained results using the different sizes for estimating the overall effort, and providing a rationale for the better results with PSU.
\end{abstract}

Keywords: Estimation, Function Points, Project Size Unit (PSU), Case Study, Non-Functional Requirements, Scope Management.

\section{Introduction}

When dealing with every activity in the real world, a common strategy is firstly to apply a top-down view on the entity of interest and then to refine and integrate 
information with a bottom-up view. Shifting this concept to the estimation process, we need before to shape the logical boundary for the activity to perform, in order to properly understand - approximately - the amount of resources needed and consequently the time and costs such activity will require.

But when a software project must be analyzed in the feasibility phased and then planned, the above described approach often seems to be difficult to be applied. Observing the experiences in ICT companies as well as reading them in technical papers, it seems there is a large distance between the experiential estimations and a statistical usage of its own project data. And there is a tendency to use very few numbers - typically product measures - in order to estimate time and costs for the overall project.

During last years the "scope management" approach from the Project Management domain [1] come in also in the Software Engineering one: some examples are the SouthernScope [2] and the NorthernScope [3] approaches, integrating the usage of functional size measurement methods with other values and thoughts able to properly represent the whole project' scope. Again, another technique called Project Size Unit (PSU) was created in 2003 for trying to catch the overall project size and some experiences have been done with it [4].

The objective of this paper is to describe the PSU technique and discussing the way it can be used with or without a FSMM for refining project's estimations, taking always in mind that the final goal is to achieve improvements in estimating projects, and that size units - whatever they are - are the way to reach that goal, not the goal itself.

Section 2 discusses the estimation issue using a FSM method, delimiting the scope and boundary for such methods. Section 3 presents the basics for PSU and the way it can be also used jointly with a FSMM. Section 4 presents a case study with the analysis of 33 sample projects sized with IFPUG v4.2 [5], COSMIC v2.2 [6] and PSU v1.01 [7], proposing first results and thoughts for improving project estimations. Section 5 will conclude with a summary of what discussed and next work planned on this issue.

\section{FSM and Estimation}

\subsection{What a FSM Method Size (And What Not)}

According to the ISO/IEC 14143-1 standard [8][9], a functional size measurement method (FSMM) takes into account only the so-called FUR (Functional User Requirements), discarding the other ones - explicit and implicit ones - called in the latest version simply "non-functional requirements". Figure 1 shows the 1998 (software) product requirement classification into $\mathrm{F} / \mathrm{Q} / \mathrm{T}$ types and the relationships between Effort and Size against the project requirement types.

The direct consequences from this ISO clarification was the exclusion of the adjustment factors in the FSMM methods standardized from the final value (i.e. the ISO/IEC 20926:2003 for IFPUG CPM v4.1 considers only the first five steps in the calculation process, calculating the solely UFP value). The rationale is that the

${ }^{1}$ The 1998 version [8] split the non-functional part into Quality and Technical Requirements. This requirement classification for a software product $(\mathrm{F} / \mathrm{Q} / \mathrm{T})$ was also received by IFPUG [5]. 


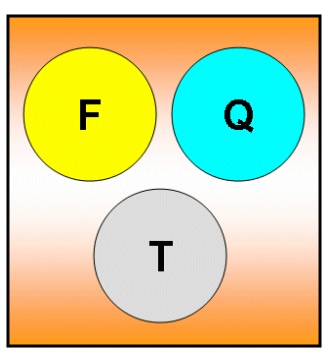

(a)

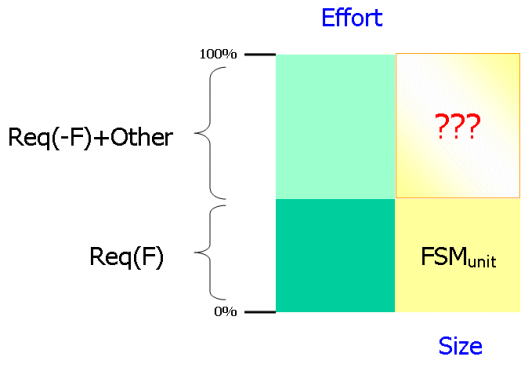

(b)

Fig. 1. (a) Requirement types according to ISO 14143-1:1998; (b) Relationship between Effort and Size against project requirements (F vs NF)

non-functional side - as initially stated also in first's Albrecht's 1979 paper on FPA [10] - has to be treated separately but in a parallel manner with the functional one. From a mathematical viewpoint, using the non-functional factors as adjustments produces effort under-estimation for such kind of tasks. A simple example can be in IFPUG FPA a TDI value lower than 35 points (therefore a VAF lower than 1): the result would be a negative contribution on the unadjusted functional size, with a lower estimated number of man-days, even if a certain amount of man-days for nonfunctional activities would be anyway yet spent/planned. Again, from an economical viewpoint, it means that the cost/day of a role typically playing a non-functional job would be lower than those ones playing functional tasks. And it seems to do not properly shape what happens [11].

\subsection{Estimation by a Functional Size Unit (fsu) with Some Open Questions}

When dealing with whatever functional size unit (fsu), the typical way to estimate the project effort can be derived from:

- a regression equation (i.e. a linear one) based on its own data;

- $\quad$ productivity figures typical from a certain system (i.e. filtering by application type, development type, size range and technology used), according to its own data or from external sources (i.e. ISBSG repository);

- The crossing between the two above information.

Thus, there are some basic and open questions to be answered:

- Productivity, as currently defined and applied, is given by the ratio between the number of fsu and the overall project effort. It can be defined a 'nominal' productivity. Being the upper value referable to a product (and only for its functional portion), while the lower value refers to the overall project (including therefore the effort for all the types of requirements: $\mathrm{F} / \mathrm{Q} / \mathrm{T} / \mathrm{O}$ ), is it a valuable number to consider for deriving projects estimates?

- Since a fsu is a valid measure only for the functional part of a software product, what about its non-functional part? 


\section{PSU: Project Size Unit}

\subsection{Background}

In 2003, during the path towards a Sw-CMM [12] ML3 certification process in an organizational unit (OU) of c.a. 80 people from a large ICT multinational company, one of the first questions to solve was to accomplish requirements from the Software Project Planning key process area, requesting to estimate efforts and costs (PP, Ac10), taking care of the overall project scope $(\mathrm{PP}, \mathrm{Ac} 2)^{2}$.

Since the projects managed by such OU were typically TLC and Energy/Utility projects with an average 55-65\% functional effort, with no enough time to properly train people with a FSMM, the point was to find out another solution for achieving the final goal taking into account also those constraints, but not too revolutionary to require too much extra time to be learned and used.

\subsection{Rationale}

The idea was to move from the boundary of the activities planned and run within a project, using the same approach Albrecht adopted for FPA, but extending the scope to all the user requirements (UR) a project has, not only FUR (Functional User Requirements), but also the Non-Functional (NFR) ones. From a Project Management viewpoint it means to consider the whole amount of activities included in a WBS, trying to estimate such amount of effort from requirements in an early stage, referring to the ISO 9000 quality definition [13], that includes both explicit and implicit requirements, where both ones generate activities and therefore effort to be estimated and planned within the project boundary.

Looking at Figure 2, our goal was to find out a new measure at the project level for approximating in early stages the overall "project size" and obtain acceptable estimates overcoming the inner scope of a FSMM, that's a functional product size measure. 'Project Size' is a term not yet defined in the ISO/IEEE/PMI glossaries. Our

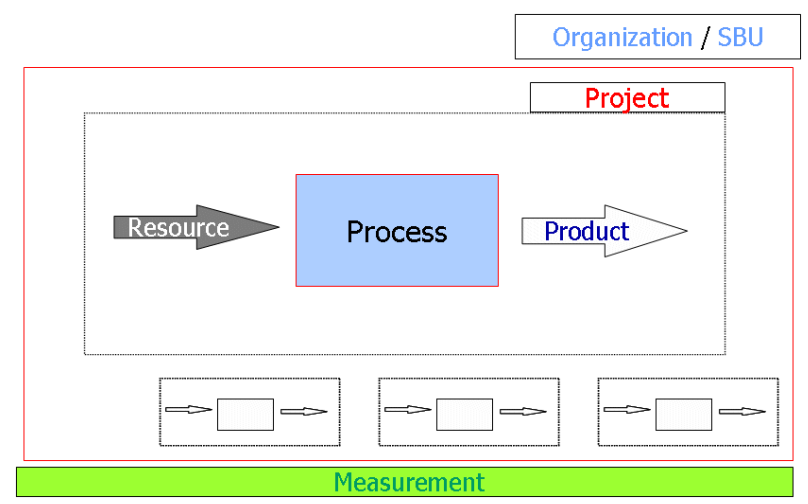

Fig. 2. STAR Taxonomy: measurable entities [14]

\footnotetext{
${ }^{2}$ The same happens also with the newer CMMI-DEV v1.2 [15] model, where the old SPP key process area was simply renamed Project Planning (PP).
} 
proposal [11], according to the above premise, is to define it as "the size of a software project, derived by quantifying the (implicit/explicit) user requirements referable to the scope of the project itself'. This term (and our own definition) was proposed to ISBSG for inclusion in a next revision of its Glossary of Terms [16].

Another objective to accomplish was to derive a mechanism valid for internal improvement first, and for external benchmarking in a second moment. The name for this new technique was Project Size Unit (PSU), definable as project management 'virtual' size technique.

\subsection{Calculation Rules}

Moving from the above premises, the FPA calculation rule was adapted to a project management logic. UFP are given by the sum of the 5 BFC (Base Functional Components) weighted by complexity.

In PSU the BFC corresponds to the WBS project tasks, firstly classified by nature: Management (M), Quality (Q) and Technical (T). The T-tasks refer to the primary processes, while the M/Q-tasks to the organizational and support processes. Other possible classifications of tasks are by requirement type (functional vs non-functional) and by SLC phase. All these classifications allow to easily gathering from early stages its own project historical data, which represent a foundation for PSU but for any process improvement initiative in general.

As in any good project management guideline, an activity should be always under control. The complexity of tasks is due by the effort of a task. The larger the effort for a task without any control/milestone in the middle, the more complex it is, therefore more risky and with higher probability to request a re-plan during the project lifetime. The PSU formula can be summarized as:

$$
P S U=\sum_{i=M, Q, T} \sum_{j=H, M, L} \text { task }_{i}^{*} \text { weight }_{j}
$$

where the weights ranges can vary according to the organizational style and definition for creating projects' WBS and can be easily derived applying on a regular basis Pareto Analysis on the project historical database (PHD). Please refer to the PSU Measurement Manual (MM) for detailed procedures and tips [4].

Another PSU characteristic is to be general-purpose: because the BFC are tasks from a project, it has no limitation about application domain, as FSMM. Therefore it can be used for a whatever kind of project (i.e. service, building, performing arts, ..).

\subsection{Automating PSU}

Since the calculation rule simply counts tasks weighted by effort ranges, differently from a FSMM, PSU can be easily automated from a project WBS within a spreadsheet or - with a macro - directly in any PM tool, needing the time for a 'click' just when creating/modifying your project plan. Requirements for automation are available and an implementation under open source software (GanttProject ${ }^{3}$ ) was yet done [17]. The added value of an integration of PSU calculation within a PM tool is the possibility to export project's data (i.e. in xml) for an easier creation/update of the

\footnotetext{
${ }^{3}$ URL: www.ganttproject.org
} 
organizational PHD, allowing several views on project's data as a base for next estimations [18][19].

\subsection{PSU: When Calculate Them?}

As suggested for FSMM, there are three typical moments in time for calculating it and gather values in the PHD: Feasibility study, Design phase and at the Closure phase.

\subsection{PSU and FSM Methods}

PSU is definable as a 'virtual' size measure because, differently from a FSMM, it needs an experiential/analogous estimate to produce a more refined estimate, compared with the 'organizational memory' (the PHD). Since the reduced time to calculate PSU, it can be used easily by SMEs what could not have time or resources for learning and applying a FSMM.

But it is possible also to use jointly PSU and FSMM: the advantage could be in early estimating the whole project effort with PSU with a better approximation than an early FSM method and after to fully calculate (also for contractual quests) fsu at the end of the Design and Closure phases.

\subsection{PSU: Internal vs. External Comparability}

IFPUG FPA allows an external comparability among projects worldwide because the system of weights and BFC ranges is the same from 1984 and never more modified. PSU born firstly as a technique for internal improvement, therefore changing periodically weights and effort ranges according to the closed projects entering into the PHD and reshaping the regression equations based on the updated database. In order to use PSU for external comparability, it is sufficient to make stable weights and effort ranges during time and/or among interested stakeholders [20].

\subsection{PSU: Available Assets}

All the PSU assets are freely available on the SEMQ website ${ }^{4}$ in several languages ${ }^{5}$. Nowadays the downloadable assets are:

- $\quad$ Measurement Manual [4];

- MS-Excel calculation sheet (traditional / agile projects);

- $\quad$ Requirements for automating PSU [19].

\section{A Case Study}

\subsection{Background and Objectives}

During a B.Sc. 2006-07 Software Engineering course at the University of Alcalà de Henares (UAH, Spain), some students worked on learning and applying FSM methods such as IFPUG and COSMIC methodologies. Moving from a previous B.Sc.

\footnotetext{
${ }^{4}$ PSU webpage: www.geocities.com/lbu_measure/psu/psu.htm

${ }^{5}$ English, Spanish, Italian.
} 
study about the conversion between IFPUG v4.2 and COSMIC v2.2 fsu, where 33 medium-sized projects were measured using both FSM methods [21] with a verification of the FSM count by an experienced senior measurer, the same projects were also sized with PSU v1.01 counting rules [22] [23] and some of the research questions above posed was investigated, in particular:

a) the relationship between PSU and IFPUG/COSMIC (if any);

b) which size unit among the three seems to be the better one for such dataset;

c) and of course, why.

\subsection{Presentation of Data Sample}

The basic data from the 33 sample projects are listed with details in the Annexes at the end of the paper. Some highlights (see Annexes B and C with full details):

- Application type: Management (16 projects), Management \& Communication (6 projects), Management \& Control (7), Management, Communication \& Control (2), Application (2);

- Estimated effort ranges: From 493 up to 2589 man/days, with an average and median distribution by requirement type closely to $44-56 \%$ (F vs. NF). The classification of effort by SLC phase was done using the Spanish Government standard METRICA3 [24].

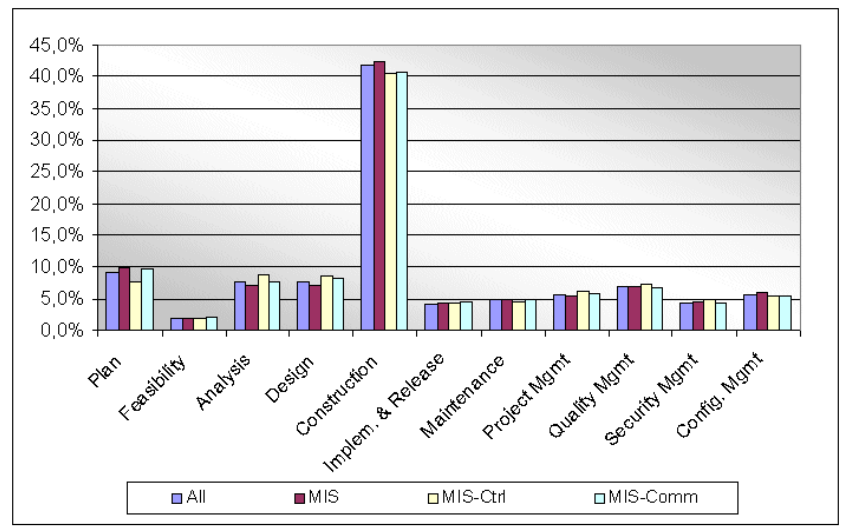

Fig. 3. Effort distribution by SLC phase according to METRICA3 [24]

Some highlights about the sizing measures (see Annexes B and C with full details):

- $\quad$ Functional Size ranges: From 109 up to 534 IFPUG UFP; from 41 up to 396 cfsu;

- PSU weighting system: The following values where assumed for the PSU calculation on the projects' sample:

○ Effort: three levels of complexity $\rightarrow$ High $(26+\mathrm{m} / \mathrm{d})$, Medium (11-25 $\mathrm{m} / \mathrm{d})$, Low $(0-10 \mathrm{~m} / \mathrm{d})$;

○ Weights: $\mathrm{H}(1.8), \mathrm{M}(1.4), \mathrm{L}(1.0)$, that's an initial set of weights we experimented on such sample. 


\subsection{First Results}

Linear regression analysis was performed using the three size units (taking care of their inner differences) in different combinations for building a size unit vs effort (using both the whole dataset and then by application type) estimation model. Since PSU values are the sum of two partial ones, derived from functional $\left(\mathrm{PSU}_{\mathrm{f}}\right)$ and nonfunctional $\left(\mathrm{PSU}_{\mathrm{nf}}\right)$ tasks elaboration, also $\mathrm{PSU}_{\mathrm{f}}$ size was considered for being compared with IFPUG and COSMIC methods. About the first issue (effort estimation models), Table 1 summarizes the main results obtained (we discarded, obviously, those categories with too less projects):

Table 1. Some Estimation Models derived from the data sample

\begin{tabular}{|c|c|c|c|c|}
\hline Id. & Relationship & Formula & $\overline{\mathbf{R}^{2}}$ & Interpret. \\
\hline \multicolumn{5}{|c|}{ Application Type: All; $n=33$} \\
\hline 1 & PSU vs Effort & $\mathrm{Y}=4.4988 \mathrm{x}+183.23$ & 0.5944 & (-) \\
\hline 2 & $\mathrm{PSU}_{\mathrm{f}}$ vs Effort & $Y=5.1825 x+669.97$ & 0.2489 & (:) \\
\hline 3 & UFP vs Effort & $Y=-0.2767+1284.3$ & 0.0019 & (2) \\
\hline 4 & Cfsu vs Effort & $Y=0.9057 x+984$ & 0.030 & (2) \\
\hline \multicolumn{5}{|c|}{ Application Type: MIS; n=16 } \\
\hline 5 & PSU vs Effort & $Y=5.2508 x+145.3$ & 0.7174 & (i) \\
\hline 6 & $\mathrm{PSU}_{\mathrm{f}}$ vs Effort & $Y=5.5899 x+781.62$ & 0.2419 & (:) \\
\hline 7 & UFP vs Effort & $Y=-4.4025 x+2738.1$ & 0.1317 & (:) \\
\hline 8 & Cfsu vs Effort & $\mathrm{Y}=0.6503 \mathrm{x}+1168+5$ & 0.0072 & (:) \\
\hline \multicolumn{5}{|c|}{ Application Type: MIS \& Control; n=7 } \\
\hline 9 & PSU vs Effort & $Y=3.6924 x+208.04$ & 0.6114 & (-) \\
\hline 10 & $\mathrm{PSU}_{\mathrm{f}}$ vs Effort & $Y=5.3581 x+500.7$ & 0.4203 & (-) \\
\hline 11 & UFP vs Effort & $\mathrm{Y}=7.2912 \mathrm{x}+1274.4$ & 0.4068 & ;) \\
\hline 12 & Cfsu vs Effort & $\mathrm{Y}=2.2822 \mathrm{x}+477.99$ & 0.1912 & (2) \\
\hline \multicolumn{5}{|c|}{ Application Type: MIS \& Communication; $n=6$} \\
\hline 13 & PSU vs Effort & $Y=6.2849 x+197.7$ & 0.7552 & (i) \\
\hline 14 & PSU $_{\mathrm{f}}$ vs Effort & $\mathrm{Y}=9.3033 \mathrm{x}+196.07$ & 0.4332 & $(-)$ \\
\hline 15 & UFP vs Effort & $\mathrm{Y}=1.1943 \mathrm{x}+686.12$ & 0.1351 & (:) \\
\hline 16 & Cfsu vs Effort & $\mathrm{Y}=0.594 \mathrm{x}+917.38$ & 0.0393 & (8) \\
\hline
\end{tabular}

From the observation of Table 1 results, it can be noted that in all cases PSU has a higher correlation with estimated effort than the other fsu, both IFPUG and COSMIC. This can be interpreted as a clear sign that there are some issues in projects that during the estimation phase having an influence on correlation; in particular:

- The non-functional effort (see the higher $\mathrm{R}^{2}$ values for "PSU vs. effort" cases against the "PSU $\mathrm{f}$ vs. effort" ones);

- A typical fsu is a product-level measure, therefore not covering such requirements, tasks and effort related to the project-level.

\subsection{Applying PSU v1.21: A What-If Analysis}

From the time of the comparative analysis, PSU calculation rules were modified. Instead taking into account M/Q tasks as an adjustment for $\mathrm{T}$ tasks (as well as VAF did referring to UFP), now all tasks - whatever their nature - are weighted by effort range. The difference comparing the same 33 sample projects sized with PSU v1.01 
Table 2. Some Estimation Models derived from the data sample (PSU v1.21)

\begin{tabular}{|c|c|c|c|c|c|}
\hline Id. & "Relationship & Formula & 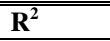 & Diff. \% & Trend \\
\hline \multicolumn{6}{|c|}{ Application Type: All; $\mathbf{n = 3 3}$} \\
\hline 1 & PSU vs Effort & $\mathrm{Y}=4.2854 \mathrm{x}+32.067$ & 0.6665 & 7.21 & $\uparrow$ \\
\hline 2 & PSU $_{\mathrm{f}}$ vs Effort & $Y=5.2603 x+222.13$ & 0.6194 & 37.05 & $\uparrow$ \\
\hline 3 & UFP vs Effort & $Y=-0.2767 x+1284.3$ & 0.0019 & -- & -- \\
\hline 4 & Cfsu vs Effort & $\mathrm{Y}=0.9057 \mathrm{x}+984$ & 0.03 & -- & -- \\
\hline \multicolumn{6}{|c|}{ Application Type: MIS; $\mathbf{n = 1 6}$} \\
\hline 5 & PSU vs Effort & $\mathrm{Y}=5.0612 \mathrm{x}-65.312$ & 0.7844 & 0.70 & $\uparrow$ \\
\hline 6 & $\mathrm{PSU}_{\mathrm{f}}$ vs Effort & $\mathrm{Y}=6.1357 \mathrm{x}+184.12$ & 0.7129 & 47.10 & $\uparrow$ \\
\hline 7 & UFP vs Effort & $\mathrm{Y}=-4.4025 \mathrm{x}+2738.1$ & 0.1317 & -- & -- \\
\hline 8 & Cfsu vs Effort & $Y=0.6503 x+1168.5$ & 0.0072 & -- & -- \\
\hline \multicolumn{6}{|c|}{ Application Type: MIS \& Control; $n=7$} \\
\hline 9 & PSU vs Effort & $Y=3.3145 x+139.5$ & 0.6800 & 6.86 & $\uparrow$ \\
\hline 10 & PSU $_{\mathrm{f}}$ vs Effort & $Y=-1.0351 x+1140.1$ & 0.0802 & -34.01 & $\downarrow$ \\
\hline 11 & UFP vs Effort & $Y=7.2912 x-1274.4$ & 0.4068 & -- & -- \\
\hline 12 & Cfsu vs Effort & $\mathrm{Y}=2.2822 \mathrm{x}+477.99$ & 0.1912 & -- & -- \\
\hline \multicolumn{6}{|c|}{ Application Type: MIS \& Communication; $n=6$} \\
\hline 13 & PSU vs Effort & $\mathrm{Y}=5.5681 \mathrm{x}-303.86$ & 0.7094 & -4.58 & $\Downarrow$ \\
\hline 14 & PSU $_{\mathrm{f}}$ vs Effort & $Y=7.3699 x-157.85$ & 0.7499 & 31.67 & $\uparrow$ \\
\hline 15 & UFP vs Effort & $\mathrm{Y}=1.1943 \mathrm{x}+686.12$ & 0.1351 & -- & -- \\
\hline 16 & Cfsu vs Effort & $\mathrm{Y}=0.594 \mathrm{x}+917.38$ & 0.0393 & -- & -- \\
\hline
\end{tabular}

and v1.21 results is an increase close to $17 \%$ (see in detail Annex E). The consequence on the results previously presented is in Table 2, updates previous results (UFP and Cfsu results are repeated for making easier the reading of results).

As evincible from the last columns, the new definition introduced in new PSU version returned improved results. In particular, it was noted an improvement using the solely $\mathrm{PSU}_{\mathrm{f}}$ part both on MIS projects $(+47.10 \%)$ as well as for MIS \& Communication ones $(+31.67 \%)$. But also looking at the overall dataset the improvement was notable $(+7.21 \%)$. On the opposite side, two lower results were noted for MIS \& Control projects (-34.01\%) and MIS \& Communication projects $(-4.58 \%)$. In order to confirm such first-level results, further validations on new datasets must be done in the near future.

\section{Conclusions and Prospects}

One of the first and more important activities in any project is the estimation phase. In the Software Engineering domain from the end of " 70 s on the usage of estimations based on a functional size unit is more and more applied. But the increasing amount of non-functional effort in software projects can reduce the probability to successfully use a fsu as the solely independent variable in a regression analysis. The evidence of such problems and limitation of FSMM is when dealing with new technologies (i.e. $\mathrm{DWH}, \mathrm{R} / \mathrm{T}$, Web applications), where there is a proliferation of interpretation for the original counting rules.

Looking at Scope Management practices from other application fields, the usage of a 'project-level' size unit can be a possible solution to complement and/or overcome the value brought out from FSMM.

Project Size Unit (PSU) is a proposal emerged in 2003 and freely available, created firstly for internal improvements in estimation practices, intimately based on 
your own organization historical data, but also available for external usage with an agreement between customer and provider on the weighting system to be adopted.

The paper has presented main outlines for such technique and relationships with two of the most used FSM methods, namely IFPUG and COSMIC FSM. A case study with 33 sample projects was presented, sizing them against IFPUG v4.2, COSMICFFP v2.2 and PSU v1.01 methods. The comparison of regression analysis among the three techniques revealed that the proposed size unit (PSU) allows to obtain better effort estimates at the higher SLC phases more than FSM units as IFPUG and COSMIC. The update of PSU counting rules with the newer PSU version v1.21 shown that such changes (counting all tasks as peer types) was right both looking from a conceptual project management viewpoint and at the obtained numerical evidences. In any case, further attention will be paid in analyzing the reasons why for 'MIS \& Control' or 'MIS \& Communication' projects results are worst.

Next steps will be a further experiment with new projects, using an automated PM tool including PSU algorithm for verifying also the pros \& cons in adopting PSU as a project size measure, observing also the effort needed for using it as well as the level of acceptance and feedbacks from estimators in project teams.

\section{Acknowledgments}

We would like to acknowledge the two students helping us in counting the 33 applications, Veronica Rubio Rodríguez and Enrique David Fernández Sanz.

\section{References}

[1] Project Management Institute, A Guide to the Project Management Body of Knowledge, 3rd edn. (2004) ANSI/PMI 99-001-2004, ISBN 1-930699-45-X

[2] Victoria Government, SouthernScope (2007) (23-05-2008), http : / www . egov . vic . gov . au / index . php?env=-innews / detail : m1816-1-1-8-s-0:n-832-1-0

[3] FISMA, NorthernScope (2007) (23-05-2008), http://www.fisma.fi/in-english/scope-management/

[4] Buglione, L.: Project Size Unit (PSU) - Measurement Manual, v1.21e (November 2007) (23-05-2008), http: / / www.geocities.com/1bu_measure/psu/psu.htm

[5] IFPUG, Function Points Counting Practices Manual (release 4.2), International Function Point User Group (January 2004) (23-05-2008), http : / / www . i fpug . org

[6] Abran, A., Desharnais, J.M., Oligny, S., St-Pierre, S., Symons, C.: COSMIC-FFP Measurement Manual, Common Software Measurement International Consortium, Version 2.2 (January 2003) (23-05-2008), http: / / www . Irgl . uqam. ca / cosmic-ffp

[7] Buglione, L.: Project Size Unit (PSU) - Measurement Manual, v1.01, Technical Report (October 2005)

[8] ISO/IEC, International Standard 14143-1 - Information Technology - Software Measurement - Functional Size Measurement - Part 1: definition of concepts (February 1998)

[9] ISO/IEC, International Standard 14143-1 - Information Technology - Software Measurement - Functional Size Measurement - Part 1: definition of concepts (February 2007) 
[10] Albrecht, A.J.: Measuring Application Development Productivity. In: Proceedings of the IBM Applications Development Symposium, GUIDE/SHARE, October 14-17, 1979, pp. 83-92 (1979) (23-05-2008), http: / / www.bfpug.com.br/Artigos / Albrecht/ MeasuringApplicationDevelopmentProductivity.pdf

[11] Buglione, L.: Some thoughts on Productivity in ICT projects, WP-2008-01, White Paper, v1.1 (March 2008) (23-05-2008),

http://www.geocities.com/1bu_measure/fpa/fsm-prod-110e.pdf

[12] Paulk, M.C., Weber, C.V., Garcia, S.M., Chrissis, M.B., Bush, M.: Key Practices of the Capability Maturity Model Version 1.1, Software Engineering Institute, CMU/SEI-93-TR025 (February 1993) (23-05-2008), http: / /www . sei.cmu.edu/pub/documents / 93.reports/pdf/tr25.93.pdf

[13] ISO, IS 9000:2005: Quality management systems - Fundamentals and vocabulary, International Organization for Standardization (September 2005)

[14] Buglione, L., Abran, A.: ICEBERG: a different look at Software Project Management, IWSM 2002 in Software Measurement and Estimation. In: Proceedings of the 12th International Workshop on Software Measurement (IWSM 2002), Magdeburg, Germany, October 7-9, 2002, pp. 153-167. Shaker Verlag (2002), http: / /www. Irgl.uqam. $\mathrm{ca} / \mathrm{publications/pdf/757.pdf} \mathrm{ISBN} \mathrm{3-8322-0765-1}$

[15] CMMI Product Team, CMMI for Development, Version 1.2, CMMI-DEV v1.2, CMU/SEI2006-TR-008, Technical Report, Software Engineering Institute (August 2006) (23-052008), http: / /www. sei.cmu.edu/publications /documents / 06 . reports / $06 \operatorname{tr} 008 . h \mathrm{tml}$

[16] ISBSG, Glossary of Terms, version 5.9.1, International Software Benchmarking Standards Group (28/06/2006) (23-05-2008),

http: / / www.isbsg.org/html/Glossary_of_Terms.doc

[17] Biagiotti, C.: Migliorare gli aspetti di stima e pianificazione di un progetto attraverso la customizzazione di un tool OpenSource di Project Management, University of Perugia, Tesi di Laurea, Perugia, Italy (July 2007)

[18] Buglione, L.: Improving Estimation by Effort Type Proportions. Software Measurement News 13(1), 55-64 (2008) (23-05-2008), http://ivs.cs.uni-magdeburg.de/ sw-eng/us/giak/SMN-08-1.htm

[19] Buglione, L.: Project Size Unit (PSU) - Calculation feature in Project Management tools - Requirements, v1.0, PSU-AU-1.00e (December 2006) (23-05-2008), http: / /www . geocities.com/1bu_measure/psu/psu.htm

[20] Buglione, L.: Tutto quello che avreste voluto sapere sui Function Point (e non avete mai osato chiedere!). In: GUFPI-ISMA meeting, Rome, Italy (May 6, 2008) (23-05-2008), http: / / www.gufpi-isma.org

[21] Rodríguez Ruiz E., Estudio estadístico de la conversión de mediciones de puntos de función IFPUG a COSMIC-FFP, University of Alcalà de Henares (Spain), Escuela Técnica Superior de Ingeniería Informática, B.Sc. Thesis (16/01/2007)

[22] Fernández Sanz, E.D.: Estudio Y Evaluación De Psu (Unidad De Medida De Proyectos) Y Estudio Estadístico De La Conversión De Mediciones Psu A Puntos De Función Ifpug, University of Alcalà de Henares (Spain), Escuela Técnica Superior de Ingeniería Informática, B.Sc. Thesis (12/06/2007)

[23] Rubio Rodriguez, V.: Estudio y Application de las PSU (Project Size Unit) para la planificación de Proyectos Software, University of Alcalà de Henares (Spain), Escuela Técnica Superior de Ingeniería Informática, B.Sc. Thesis (12/06/2007)

[24] Instituto Nacional de Administración Publica, Metodología MÉTRICA versión 3, TIC0529-01 (23-05-2008), http: / /www. csi.map.es/csi/metrica3/ 


\section{Annex A: List of Acronyms}

\begin{tabular}{|c|c|}
\hline Acronym & Term / Definition \\
\hline$\overline{\mathrm{Ac}}$ & Activity \\
\hline B.Sc. & Bachelor diploma \\
\hline $\mathrm{BFC}$ & Base Functional Components \\
\hline CMM & Capability Maturity Model \\
\hline CMMI-DEV & CMM Integration for Development \\
\hline COSMIC & Common Software Measurement International Consortium \\
\hline CPM & Counting Practice Manual \\
\hline DWH & Data WareHouse \\
\hline $\mathrm{F} / \mathrm{Q} / \mathrm{T}$ & Functional / Quality / Technical \\
\hline $\mathrm{F} / \mathrm{Q} / \mathrm{T} / \mathrm{O}$ & Functional / Quality / Technical / Organizational \\
\hline FISMA & Finnish Software Metrics Association \\
\hline FP & Function Point \\
\hline FPA & Function Point Analysis \\
\hline FSM & Functional Size Measurement \\
\hline FSMM & FSM Method \\
\hline fsu & Functional Size Unit \\
\hline FUR & Functional User Requirement \\
\hline ICT & Information \& Communication Technology \\
\hline IEC & International Electrotechnical Commission \\
\hline IEEE & Institute of Electrical and Electronics Engineers \\
\hline IFPUG & International Function Point Users Group \\
\hline ISBSG & International Software Benchmarking Standards Group \\
\hline ISO & International Organization for Standardization \\
\hline KPA & Key Process Area \\
\hline LOC & Line Of Code \\
\hline ML & Maturity Level \\
\hline NESMA & Netherlands Software Metrics Users Association \\
\hline NF & Non-Functional \\
\hline NFR & Non-Functional Requirement \\
\hline $\mathrm{OU}$ & Organizational Unit \\
\hline PA & Process Area \\
\hline PHD & Project Historical Database \\
\hline PM & Project Management \\
\hline PMI & Project Management Institute \\
\hline PP & Project Planning \\
\hline PSU & Project Size Unit \\
\hline $\mathrm{R} / \mathrm{T}$ & Real/Time \\
\hline SME & Small-Medium Enterprise \\
\hline SPP & Software Project Planning \\
\hline STAR & Software Taxonomy Revised \\
\hline Sw-CMM & Software Capability Maturity Model \\
\hline TDI & Technical Degree of Influence \\
\hline TLC & Telecommunication \\
\hline UAH & Universidad de Alcalá de Henares \\
\hline UFP & Unadjusted Function Point \\
\hline UR & User Requirements \\
\hline VAF & Value Adjustment Factor \\
\hline WBS & Work Breakdown Structure \\
\hline
\end{tabular}




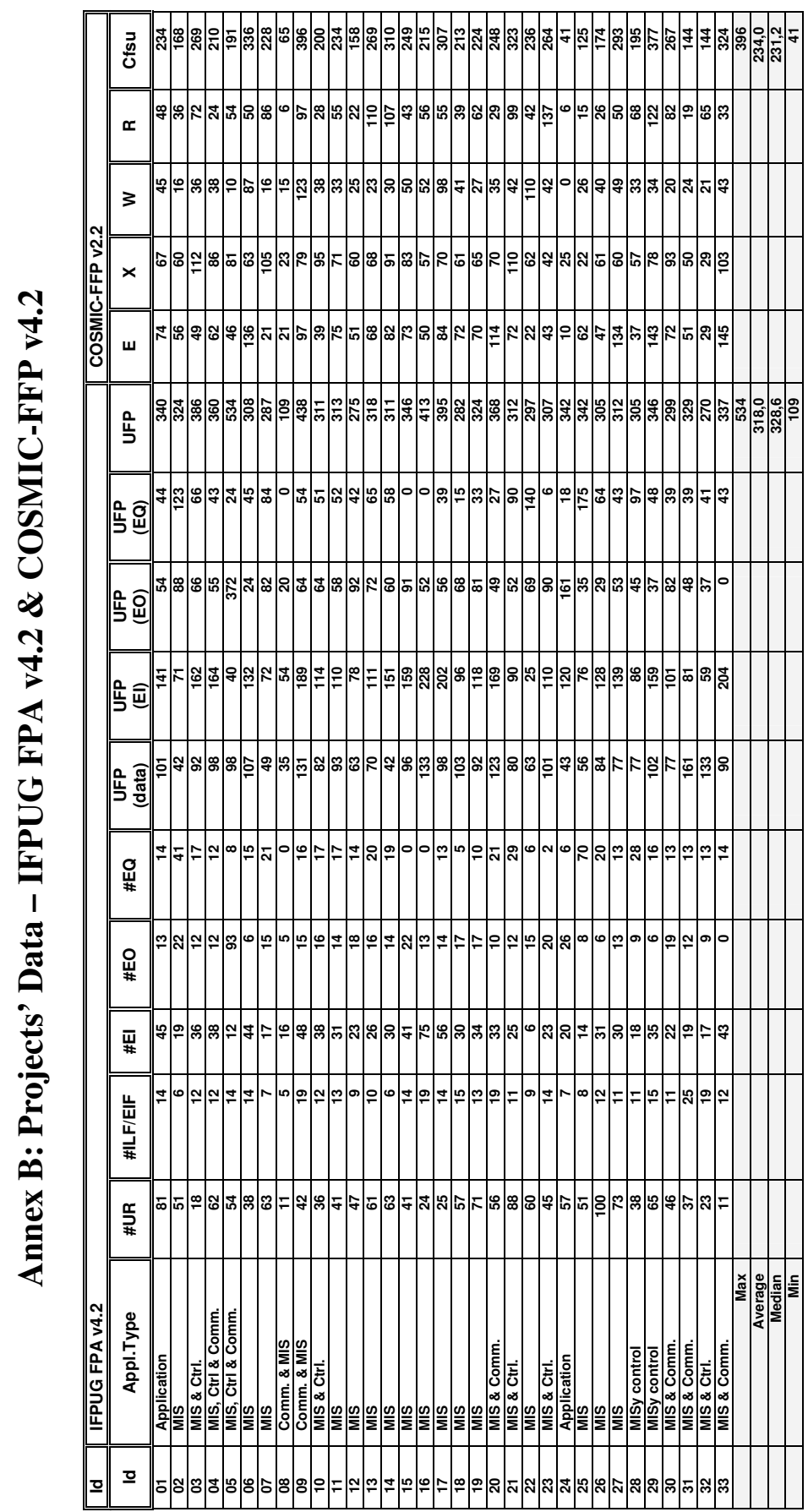




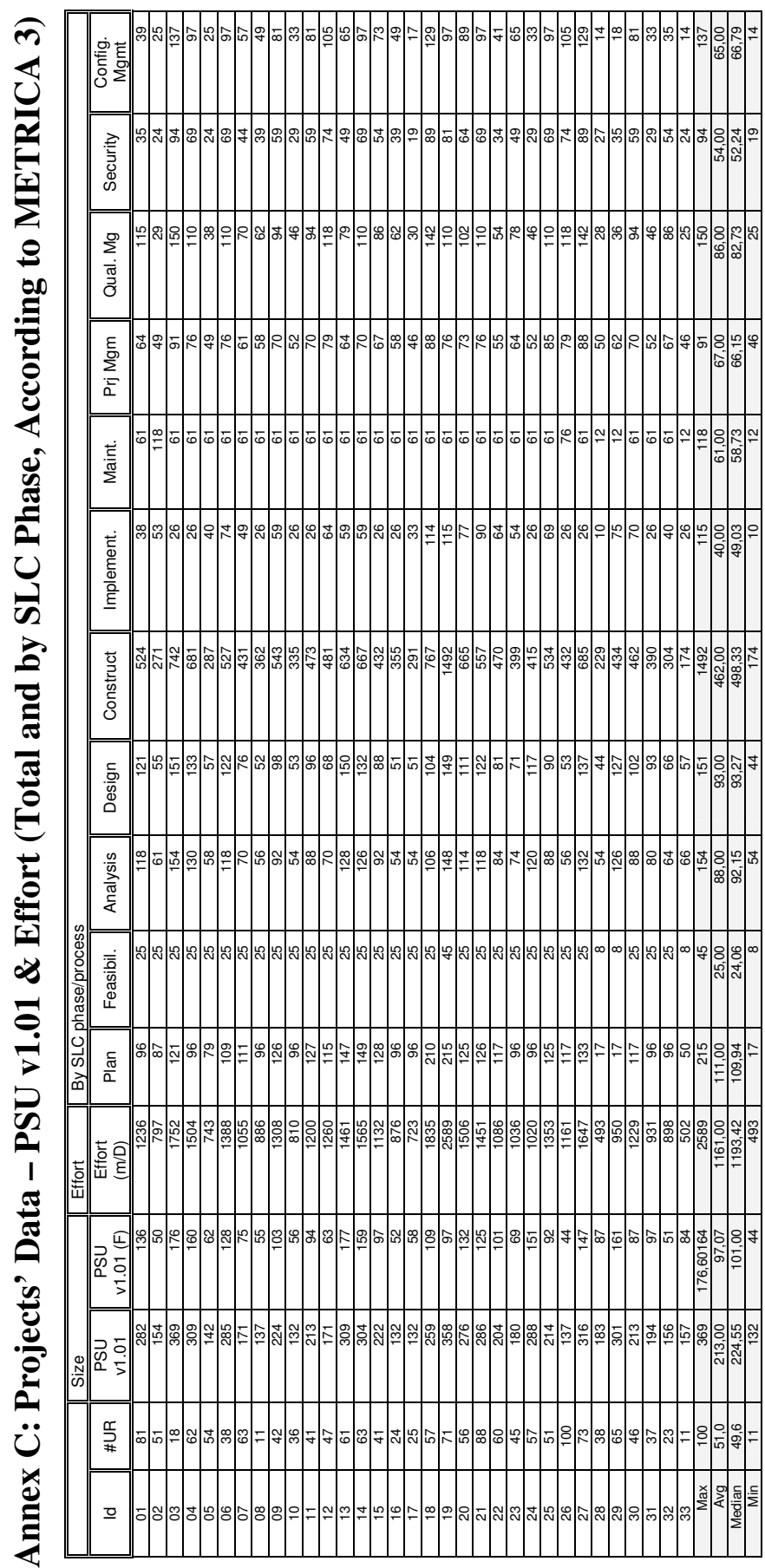




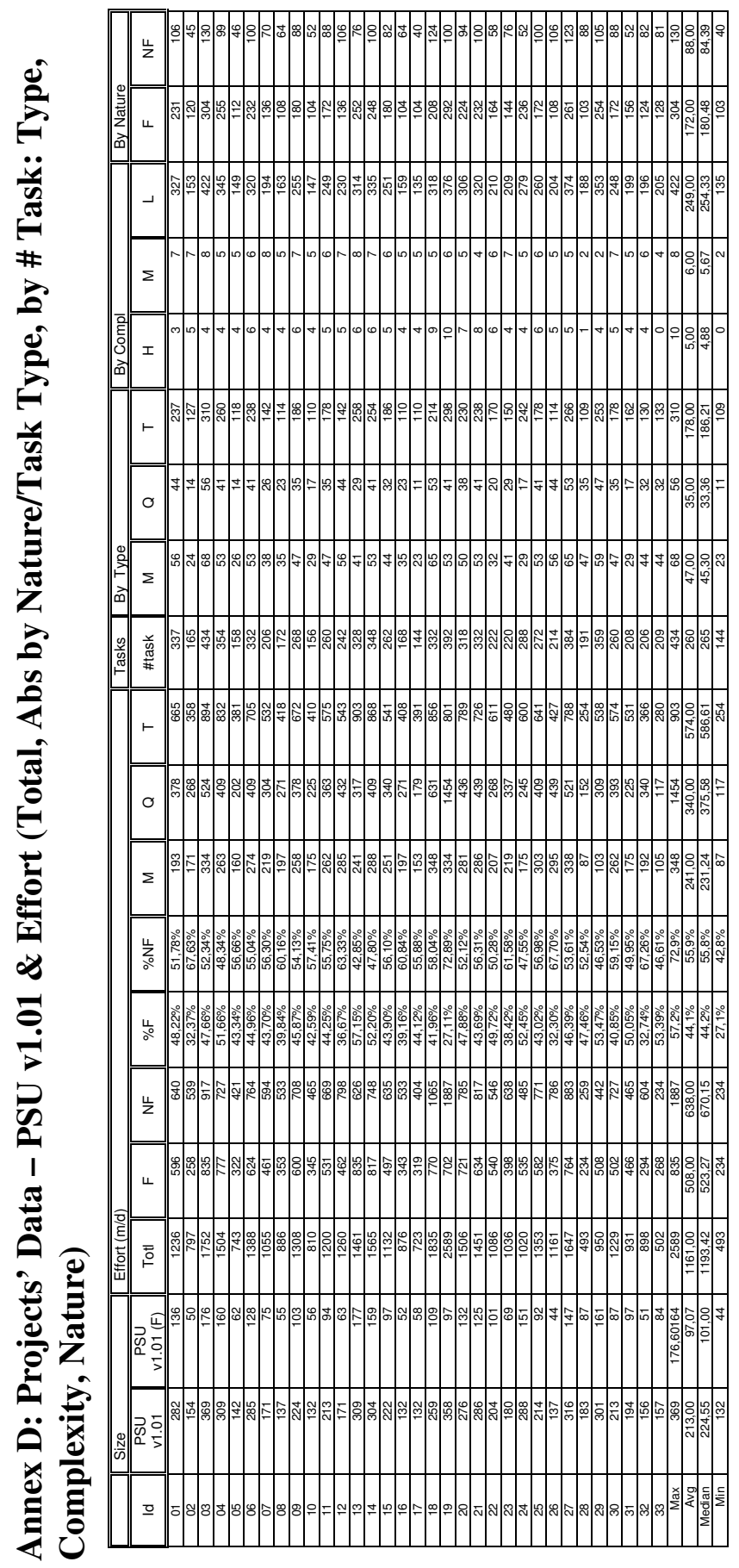




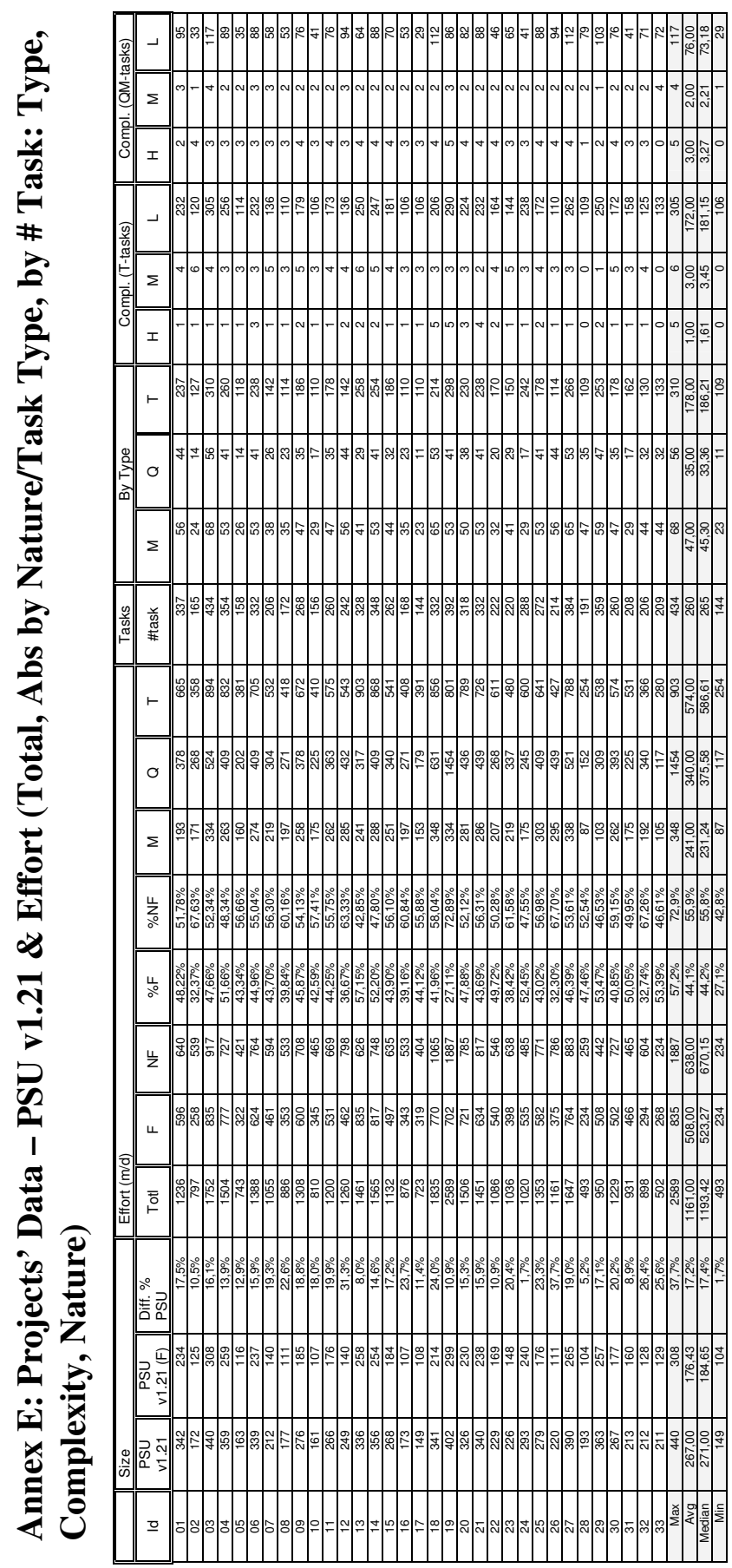

